\title{
Condicionantes Motivacionais Escolha Residência Multiprofissional Atenção Básica
}

\section{Motivational Factors in the Choice of Multiprofessional Residency in Primary Care}

\author{
Jamir Sardá Júnior ${ }^{I}$ \\ Israel Domingos Dias ${ }^{I}$ (iC \\ Marco Aurélio Da Ros ${ }^{I}$ (D) \\ Gabrielly Bos de Oliveira ${ }^{I}$ iD
}

\section{PALAVRAS-CHAVE}

- Residência Multiprofissional.

- Saúde Coletiva.

- SUS

- Motivação.

Introdução: A residência multiprofissional (RM) é uma modalidade de pós-graduação que agrega graduados de diversas áreas da saúde. Trata-se de uma modalidade de aprendizado em serviço. O objetivo deste estudo foi investigar os condicionantes motivacionais para a escolha do programa de RM de uma universidade situada no Vale de Itajaí, em Santa Catarina, por seus candidatos. Método: Para a realização desta pesquisa, adotou-se uma abordagem mista, quantitativa e qualitativa, em que se aplicaram questionários aos alunos da graduação do ensino superior e realizaram-se entrevistas com residentes do segundo ano. O número de participantes da pesquisa foi estipulado considerando o número total de alunos em sala de aula e, dentre estes, aqueles que tinham interesse em ingressar na RM. Participaram da amostra 123 alunos, dos quais 81 não tinham interesse em realizar a RM e 42 gostariam de participar do programa. Na análise dos dados oriundos dos questionários, utilizou-se a estatística descritiva (frequência simples e relativa). Os conteúdos da entrevista foram submetidos à análise de conteúdo. Participaram da aplicação de questionários 123 alunos dos últimos períodos dos cursos de Psicologia, Educação Física, Fisioterapia, Fonoaudiologia, Medicina, Enfermagem e Nutrição; além disso, foram entrevistados oito residentes. Resultados: Constatou-se que $62 \%$ dos participantes buscam a residência como uma forma de capacitação profissional, dois quais $21 \%$ têm interesse em atuar em saúde coletiva/SUS, e outros 19\% referem ter interesse em participar da residência em função da atuação multiprofissional. Conclusões: A análise de conteúdo indica que os residentes percebem como desafios a tarefa de atuar no sistema público devido a falta de mão de obra, dos aparelhos instrumentais e saturação de demanda e relações interpessoais com os colegas de outras especialidades. Entre os fatores motivacionais para entrada dos estudantes no programa de $R M$, destacam-se a experiência profissional, o interesse em saúde coletival SUS e o comprometimento social. A presença de profissionais que são referência na saúde coletiva também emergiu como um aspecto motivador importante na escolha dos profissionais por essa área de atuação. Os resultados deste estudo reforçam o importante do papel da RM na formação profissional visando atendimento em saúde coletiva. 


\section{KEYWORDS}

- Multiprofessional Residency.

- Collective Health.

- SUS.

- Motivation.

Recebido em 9/3/20

Aceito em 19/4/20

\section{ABSTRACT}

Introduction: Multiprofessional residency (MR) is a postgraduate program which brings together graduates from diverse areas of health. It is a model of in-service learning. The objective of this study was to investigate the motivational factors behind the candidates' decision to choose the MR program of a university located in the Vale of Itajai - SC. Method: For this research a mixed, quantitative and qualitative approach was used, applying questionnaires to undergraduate students and interviews with second year residents. The entire study sample was composed of 123 undergraduate students in the final semester of the Psychology, Physical Education, Physiotherapy, Speech Language Pathology, Medicine, Nursing and Nutrition courses: 81 respondents were not interested in MR and 42 were interested in participating in the program. Data from the questionnaires were analyzed using descriptive statistics (simple and relative frequency). A further eight student residents were interviewed. The contents of the interviews were submitted to content analysis. Results: It was found that $62 \%$ of the participants seek the residency program as a form of professional training, 21\% are interested in working in Collective Health/SUS (Unifed Health Service), another 19\% of the participants reported an interest in participating in the residency because of multiprofessional work. Conclusion: The content analysis indicates that residents perceive the task of operating within the public health system as a challenge due to the lack of manpower, instrumental devices coupled with saturated demand and interpersonal relationships with colleagues in other specialties. As motivational factors for their entry into the multiprofessional residency program students cited the professional experience, interest in Collective Health/SUS and social commitment. The presence of professionals who are a reference in collective health also emerged as an important motivational aspect in professional choosing to move into this field. The results of this study reinforce the importance of the role of the multiprofessional residency in vocational training aimed geared toward collective health care.

\section{INTRODUÇÃO}

A residência multiprofissional (RM) surge com um meio de capacitação e desenvolvimento profissional na área da saúde, propondo uma prática interdisciplinar que atenda às necessidades do Sistema Único de Saúde (SUS). Trata-se também de um processo de mudança no sistema de atendimento na área da saúde que parte de uma desconstrução do modelo biomédico com foco na doença e de uma formação técnicainstrumental para um modelo que privilegia um olhar estendido sobre o ser e o processo do adoecer, com uma ênfase biopsicossocial e crítica, no caso da RM, com a determinação social como a base do entendimento. Essa abordagem propicia ao profissional o desenvolvimento de competências, habilidades, conhecimentos e capacidade relacional, visto que aqui os saberes são compartilhados entre os demais profissionais da área da saúde ${ }^{1}$.

A RM existe desde 1978, sendo reconhecida em 2005 a partir da promulgação da Lei no 11.129 . A RM é regida pelos princípios e diretrizes do SUS, visando atender às necessidades socioepidemiológicas da população brasileira. Foi regulamentada somente em 2009 por meio da Portaria Interministerial $\mathrm{n}^{\circ} 1.077^{2}$. O programa de RM tem duração de dois anos, com carga horária total de 5.760 horas, das quais $1.152(20 \%)$ são destinadas às atividades teóricas e 4.608 (80\%) às atividades práticas (modalidade treinamento em serviço) do exercício da profissão. A residência é considerada uma modalidade de ensino lato sensu, com aprendizado em serviço, que abrange os cursos que fazem parte da área da saúde e exigem dedicação exclusiva ${ }^{3}$.

Os programas de RM são regulamentados pelo Ministério da Educação em parceria com o Ministério da Saúde. A formação em saúde vem sendo discutida desde o final da década de 1980, e, desde então, muitas estratégias têm sido estudadas para aproximar as instituições de ensino e os serviços de saúde, com participação da comunidade. Nesse contexto, a RM estimula uma prática de ensino-aprendizagem apoiada em vivências dos estudantes na realidade concreta dos serviços de saúde, agregando as necessidades da comunidade e a produção de conhecimento. Ademais, a RM é desenvolvida em conjunto com os gestores e as instituições formadoras, orientados pelos princípios e pelas diretrizes do SUS. Essa aproximação dos gestores com os centros formadores do profissional demonstra uma inovação no que tange à formulação de políticas para a formação de trabalhadores na área da saúde e para o SUS 4 .

A RM abrange 13 áreas da saúde, a saber: Biomedicina, Ciências Biológicas, Educação Física, Enfermagem, Farmácia, Fisioterapia, Fonoaudiologia, Medicina Veterinária, Nutrição, Odontologia, Psicologia, Serviço Social e Terapia Ocupacional ${ }^{2}$. Para ser caracterizada como RM, é necessário contar com pelo menos três profissionais de diferentes áreas da saúde. Durante um período de dois anos, os residentes recebem do governo uma bolsa no valor de $\mathrm{R} \$ 3.330,43^{5}$.

Diante desses fatores, a RM foi concebida com o intuito de formar profissionais de saúde com um novo perfil, operando na perspectiva de integração profissional entre as diversas áreas da saúde. É baseada em práticas de humanização e comprometimento com o saber e poder coletivo, além da capacidade de responder às reais necessidades de saúde dos usuários. Sendo assim, cria um processo de identidade profissional que não termina na escolha do curso de graduação, pois é necessária uma identificação com a área de atuação. A construção da identidade é formada sobre três aspectos - os grupos, os processos de identificação e o esquema corporal -, os quais estão relacionados ao que o indivíduo quer ser e ao que ele não quer. A escolha profissional é uma construção

REVISTA BRASILEIRA DE EDUCAÇÃO MÉDICA

2 44 (3) : e083; 2020 
dialética, e a identidade profissional é edificada nas relações do sujeito com pessoas e fatos importantes durante sua vida $a^{6,7}$.

Por sua vez, o exercício profissional é um meio de expressar os valores, os interesses e as características do indivíduo ${ }^{6,8}$. A busca por uma profissão também perpassa pelas condições de oferta de trabalho e pela realidade social em que o indivíduo está inserido. Em muitos contextos, a sociedade brasileira acaba por abarcar o trabalho somente como uma possibilidade de sobrevivência, descartando a realização e o crescimento pessoal. Isso se dá em virtude das condições salariais, da alta taxa de desemprego e dos fatores de vulnerabilidade social associados ao contexto de vida do sujeito que dificultam a inserção no mercado de trabalho.

Em contrapartida, para aqueles que podem escolher uma profissão, o trabalho é visto como uma busca por status e independência familiar e também como necessidade de sustento, em que o significado atribuído pelo sujeito ao trabalho reflete em sua expectativa quanto à escolha profissional. Para tanto, a escolha profissional tem coerência com os interesses, os objetivos e as necessidades pessoais do sujeito.

Com base nesses pressupostos e nesse cenário, esta pesquisa teve por objetivo investigar os condicionantes motivacionais para a escolha de um programa de RM realizado em uma universidade situada no Vale de Itajaí, em Santa Catarina.

\section{METODOLOGIA}

Trata-se de um estudo pautado em duas perspectivas metodológicas: qualitativa e quantitativa. As estratégias de pesquisa foram desenvolvidas em três momentos. No primeiro momento, aplicou-se aos graduandos com interesse em outros cursos de pós-graduação um questionário contendo seis perguntas fechadas. O segundo momento aconteceu com a aplicação de um questionário contendo seis perguntas fechadas e duas abertas aos graduandos que tinham interesse em cursar a RM. Por fim, o terceiro momento se deu com a entrevista semiestruturada com residentes. A escolha dos residentes foi de acordo com a disponibilidade e o interesse deles, por meio de contato prévio e explanação dos objetivos da pesquisa.

A fase de campo começou com o convite de participação via explanação dos objetivos e aspectos éticos da pesquisa que constam no Termo de Consentimento Livre e Esclarecido (TCLE). Apresentouse a proposta de pesquisa aos coordenadores dos cursos de Psicologia, Educação Física, Fisioterapia, Fonoaudiologia, Medicina, Enfermagem e Nutrição com o objetivo de obter autorização para a coleta de dados dos estudantes e dos respectivos cursos que estavam em fases finais (nona e décima fases) da graduação. Após a autorização dos coordenadores, os questionários foram aplicados em sala de aula, segundo a disponibilidade de data e horário dos professores. Em sala de aula, inicialmente foram esclarecidos aos participantes os objetivos da pesquisa, bem como seus riscos e benefícios. Após esse contato inicial, realizou-se o levantamento de estudantes que tinham interesse em ingressar na RM. Os estudantes interessados na RM foram convidados a participar da pesquisa. Em seguida, coletaram-se as assinaturas do TCLE e entregaram-se os questionários para o preenchimento.

O número de participantes da pesquisa foi estipulado considerando o número total de alunos em sala de aula e, destes, aqueles que tinham interesse em ingressar na RM. Participaram da amostra 123 alunos, dos quais 81 não tinham interesse em realizar a $R M$ e 42 gostariam de participar do programa.
Subsequentemente, para a realização das entrevistas com os residentes ingressos no programa de $\mathrm{RM}$, foi necessário entrar em contato com a coordenação da RM da instituição a fim obter a permissão para realizar a pesquisa com os alunos do último ano de residência. Realizou-se um encontro com os residentes em sala de aula, quando se explanaram os objetivos da pesquisa e levantou-se o número de interessados em participar da entrevista. Posteriormente, foi marcado um horário para a entrevista que durou em média 20 minutos. Participaram da entrevista oito residentes. $\mathrm{Na}$ análise dos dados oriundos dos questionários, utilizou-se a estatística descritiva (frequência simples e relativa). Os conteúdos da entrevista foram submetidos à análise de conteúdo 9 .

A pesquisa foi submetida ao Comitê de Ética em Pesquisa da Univali e aprovada (Parecer $n^{\circ}$ 2.235.734), observando todos os aspectos éticos preconizados na pesquisa com seres humanos.

\section{RESULTADOS E DISCUSSÃO}

Foram convidados a participar da pesquisa 199 acadêmicos, dos quais 123 aceitaram participar e responderam ao questionário por terem interesse em realizar uma especialização, e entrevistaram-se oito residentes. Primeiramente, serão descritos os dados oriundos dos questionários e depois os dados emergentes da análise de conteúdo.

Quanto ao projeto profissional, foi observado que $71 \%$ dos participantes afirmaram ter um. Em relação à grade curricular ofertada pela universidade e à preparação para inserção no mercado de trabalho, $71 \%$ dos alunos mencionaram que sentem parcialmente preparados. Quando questionados sobre a necessidade de um curso complementar para que possam atuar na área que desejam, 93\% dos estudantes afirmaram que sim, pois, segundo eles, a graduação ofereceu poucas ou nenhuma oportunidade de aprendizagem na área de interesse. Quando questionados se o curso de pós-graduação era necessário logo após a graduação, 67\% relataram que haveria necessidade de cursar a pósgraduação logo em seguida. Sobre os cursos de pós de graduação, $42 \%$ dos alunos de graduação referiram o desejo de cursar uma especialização.

De acordo com os resultados apresentados na Tabela 2, 69\% dos alunos de graduações afirmaram ter um projeto profissional. Quanto à grade curricular e à preparação para o mercado de trabalho, $87 \%$ mencionaram que se sentem parcialmente preparados. Sobre a necessidade de um curso complementar para atuação na área desejada, 92\% afirmaram que isso é importante. Quando questionados sobre a necessidade de um curso de pós-graduação logo após a graduação, os resultados foram equilibrados: $52 \%$ afirmaram que haveria necessidade imediata de cursar a pós-graduação.

A respeito da motivação para realizar a RM, nas questões objetivas, a oportunidade de experiência profissional (68\%) foi apontada como o maior motivador, seguida de interesse pelo SUS (43\%) e envolvimento com causas sociais $(42 \%)$.

As respostas oriundas das questões abertas corroboram os resultados obtidos nas questões fechadas, demonstrando que a maior motivação dos graduandos para a realização da RM está na oportunidade de capacitação/ experiência profissional (Tabela 2,68\%), seguido pelo interesse em saúde coletiva/SUS (Tabela 2, $42 \%$ e $43 \%$, respectivamente) como uma das razões de escolha dos alunos da graduação pela RM.

Os dados apresentados pelos alunos que desejam realizar a RM (Tabela 2) e por aqueles que optam por outros cursos (Tabela 1) mostram

REVISTA BRASILEIRA DE EDUCAÇC̃̃ MÉDICA

3 44 (3) : e083; 2020 


\begin{tabular}{|c|c|c|}
\hline \multicolumn{3}{|c|}{$\begin{array}{l}\text { Descrição das respostas oriundas dos questionários aplicados em } \\
\text { sala de aula com alunos que tinham como objetivo realizar um } \\
\text { curso de pós-graduação }\end{array}$} \\
\hline Projeto profissional & & Número (percentual) \\
\hline & Sim & $57(71 \%)$ \\
\hline & Não & $22(27 \%)$ \\
\hline & $\mathrm{m}$ resposta & $2 \quad(2 \%)$ \\
\hline
\end{tabular}

Pretende realizar um curso de pós-graduação

$\begin{array}{lcc}\text { Sim } & 81 & (100 \%) \\ \text { Não } & 0 & (0 \%)\end{array}$

Adequação da grade curricular para a inserção no mercado de trabalho

Número (percentual)

$\begin{array}{ccc}\text { Completamente preparado } & 10 & (12 \%) \\ \text { Parcialmente preparado } & 65 & (71 \%) \\ \text { Pouco preparado } & 6 & (7 \%)\end{array}$

Curso complementar para adequação ao mercado de trabalho

Número (percentual)

$\begin{array}{lcc}\text { Sim } & 75 & (93 \%) \\ \text { Não } & 6 & (7 \%)\end{array}$

Necessidade de realização de curso de pós-graduação imediatamente após a graduação

Número (percentual)

$\begin{array}{lll}\text { Sim } & 55 & (67 \%) \\ \text { Não } & 26 & (33 \%)\end{array}$

Modalidade de curso de pós-graduação

Número (percentual)

$\begin{array}{ccc}\text { Especialização } & 23 & (42 \%) \\ \text { Mestrado } & 34 & (17 \%) \\ \text { Pós-graduação (outro) } & 14 & (28 \%) \\ \text { Residência em outra área da saúde } & 10 & (12 \%)\end{array}$

Fonte: Elaborada pelos autores

semelhanças nas respostas. Ambos os grupos têm a percepção de que é necessário um curso de pós-graduação. Em sua maioria, os dois grupos afirmaram que têm um projeto profissional. A maior diferença das duas amostras é sobre a percepção do caráter imediato na realização da pós-graduação, e os que optaram por outras modalidades que não a RM apresentam um índice maior no imediatismo de realizar uma pósgraduação. De acordo com os dados, o curso que os estudantes realizarão depois da graduação não altera significativamente a percepção deles a respeito do preparo oferecido pela grade curricular, o que pode ser fruto de um caráter mais generalista dos cursos de graduação em saúde. Esse aspecto forçaria os alunos a buscar por especializações nas áreas de atuações que desejam.

A seguir serão descritas as categorias que emergiram da análise de conteúdo das entrevistas com os residentes já ingressos no programa de RM.

Podemos perceber, com base no conteúdo que emergiu das entrevistas com os residentes do segundo período, que existem diferentes motivações para a escolha da RM, as quais foram assim categorizadas: Motivações

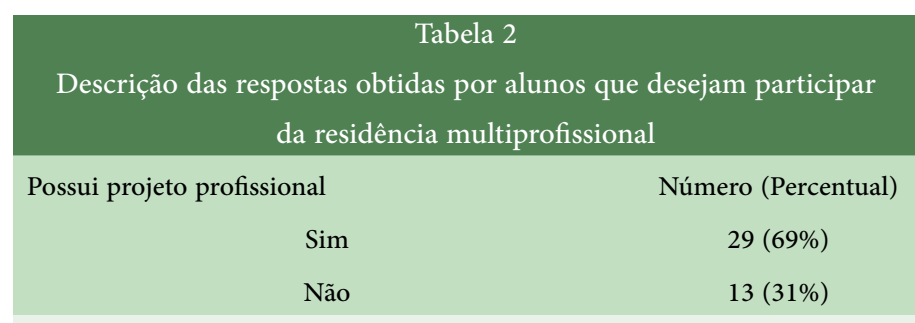

Pretende realizar um curso de pós-graduação

$\begin{array}{cc}\text { Sim } & 42(100 \%) \\ \text { Não } & 0 \quad(0 \%)\end{array}$

Adequação da grade curricular para a inserção no mercado de trabalho

Número (percentual)

$$
\begin{gathered}
\text { Completamente preparado } \\
\text { Parcialmente preparado } \\
\text { Pouco preparado }
\end{gathered}
$$$$
4 \quad(9 \%)
$$

Curso complementar para adequação ao mercado de trabalho

Número (percentual)

$\begin{array}{cc}\text { Sim } & 39(92 \%) \\ \text { Não } & 3(8 \%) \\ \text { Necessidade de curso de pós-graduação } & \text { Número (percentual) } \\ \text { Sim } & 22(52 \%) \\ \text { Não } & 20(48 \%)\end{array}$

Aspectos motivacionais para a realização da RM Número (percentual)

$$
\begin{aligned}
& \text { Interesse pelo SUS } \\
& \text { Interesse pela área hospitalar } \\
& \text { Oportunidade de bolsa }
\end{aligned}
$$$$
22(43 \%)
$$

Oportunidade de experiência profissional

Alguém próximo que trabalha

Envolvimento em causas sociais

Oportunidade de trabalho concursado

$8(19 \%)$ individuais, sociais, institucionais e referentes a políticas públicas.

Entre as motivações individuais, foi possível identificar diferentes elementos que determinaram a escolha da RM, descritos nas subcategorias experiência profissional e interesse em saúde coletiva/SUS.

\section{Categoria: motivações individuais}

\section{Experiência profissional}

Foi identificado que quatro dos oito residentes optaram por realizar a RM como uma forma de ganhar experiência profissional, o pode ser percebido na fala de R3 (psicóloga): "estender a área acadêmica com a área profissional até pela um pouco de insegurança, né?! Então a residência traz um pouco de segurança porque você está atuando e estudando numa área, né? Ter uma tutoria/uma preceptoria que podem te auxiliar".

Um dos aspectos característicos da residência é a prática supervisionada, considerada uma importante estratégia de capacitação profissional. Embora isso seja uma etapa na formação dos médicos, para outros profissionais de saúde é um novo recurso. De modo geral, 
os residentes consideram a RM um meio importante para aplicar o conhecimento, melhorar o desempenho no trabalho, utilizar o conteúdo aprendido e reconhecer as situações corretas de aplicações, favorecendo assim uma melhor atuação no exercício da profissão ${ }^{10}$. A percepção da residência como uma forma de capacitação para o mercado de trabalho também é trazida por outros entrevistados:

[...] na verdade foi a experiência profissional porque querendo ou não a gente faz 5 anos de faculdade, mas não tem experiência nenhuma, né?! Então foi o que me levou a ter mais segurança para o mercado de trabalho (R2, enfermeira).

Eu queria ter feito porque eu me achava muito insegura na técnica (R1, dentista).

Portanto, é possível que o distanciamento percebido pelos alunos entre o mercado de trabalho e a graduação seja um fator relevante para que a residência se torne um meio de aprimorar o desenvolvimento profissional. Sendo assim, ao estar inserida na prática profissional, a residência permite ao residente desenvolver não apenas habilidades e competências que são necessárias às especialidades, mas também vivências cotidianas que ampliem suas concepções de cuidado em saúde. Estudos comprovam que a RM tem capacitado e provido experiência para atuação no serviço público, formando profissionais mais seguros de suas atuações ${ }^{10,11}$.

\section{Saúde coletiva/SUS}

A partir da década de 1980, o SUS foi regulamentado e passou ter suas diretrizes especificadas. Com a implantação do SUS, novos desafios foram se apresentando para a academia e para os pesquisadores em saúde coletiva. Tratava-se de questões que ultrapassavam os temas político-ideológicos da reforma sanitária. No tocante às universidades e aos pesquisadores, os desafios foram os seguintes: desenvolver novas estratégias para o aprimoramento da qualidade dos cuidados e do impacto na saúde da população, estabelecer a coerência entre equidade e oferta de ações que incorporem os avanços da ciência e tecnologia, e formar e capacitar o pessoal de saúde para as necessidades do país e da sociedade ${ }^{12}$.

Uma das estratégias encontradas para superar os desafios que surgiram com a criação do SUS foi a capacitação de profissionais por meio de uma mudança nos currículos dos cursos de saúde. Para tanto, adotou-se um modelo pedagógico que permitia ao aluno aprender a aprender de maneira ética, humana e competente, de modo a beneficiar a população. O indivíduo deveria ter uma formação geral e estar apto a exercer a profissão ao sair da universidade ${ }^{13}$.

A RM acaba por estender ao aluno graduado na universidade uma oportunidade de conhecer na prática o contexto da saúde coletiva/SUS e a filosofia que permeia o SUS. Esses fatores ficam claros na fala de R6 (médico): "Primeiro que eu queria atenção básica, eu queria Medicina da Família e Comunidade, só que eu acho que não tem como eu pensar Medicina da Família e Comunidade sem ser multi, né?!”.

Outro aspecto associado a esses fatores é o interesse na área de saúde coletiva e no SUS: "Foi na verdade a linha de pesquisa que eu tinha na universidade. Assim, desde muito cedo eu fui começando a pesquisar sobre o Nasf, sobre o SUS... gostava dessa área da saúde coletiva" (R7, fisioterapeuta). A afinidade com a saúde coletiva e os princípios do SUS pode estar presente antes mesmo do ingresso na faculdade, como relata R4 (fonoaudióloga): "Vivenciar um pouco o SUS porque era um dos meus sonhos, continuar trabalhando nessa área, eu sempre me identifiquei, eu sempre busquei". Para tanto, uma grade curricular que aborde ou priorize a formação em saúde coletiva na atenção básica e em pesquisas na área pode motivar os alunos a realizar a residência. De acordo com Freire, Guimarães, Henriques e Chaves ${ }^{13}$, a construção de um currículo é reflexo de uma construção ideológica transmitida de um grupo para outro.

\section{Fatores institucionais}

Durante as entrevistas, a instituição se mostrou como uma das variantes influenciadoras na escolha da RM. De acordo com R1 (dentista): "Os professores foram essenciais assim, né? Tanto pela sensibilização quanto já no decorrer da graduação. Por gostar da saúde coletiva, o SUS, então acho que a universidade teve bastante presente nesse sentido de me sensibilizar e gostar da área da pública". A fala da residente ilustra a importância da universidade ter profissionais articulados com as políticas e práticas do SUS, professores que sensibilizem os seus alunos a ter um olhar para o sistema público de saúde. Dessa forma, o professor, como elo entre teoria, realidade e prática dentro do processo ensino-aprendizagem, corporificase como instrumento para a formação de um profissional preocupado com suas práticas de trabalho.

Ademais, R6 (médico) acrescenta: "Na verdade a instituição em si foi um contra. Pela toda sua trajetória ser privada, né?! Mas o professor que é referência na luta pelo SUS está lá, deve ter alguma coisa diferente". Dessa forma, estar próximo a profissionais do movimento do SUS e que representam a filosofia da RM foi fundamental para R6 optar pela residência.

Todavia, R3 (psicóloga) pontua outro aspecto importante para sua escolha: "Eu acho que a proposta do programa de residência daqui era interessante por ele estar discutindo também política... Acho que me ganhou muito foi o local da residência aqui e a proposta". Podemos perceber nesse conteúdo a importância da proposta da residência que também pode ser interpretada como um projeto político-pedagógico, que também tem a função de expressar os valores e princípios educacionais e políticos adotados pelo programa, fruto de uma produção coletiva, com o objetivo de nortear e conduzir o processo de formação, buscando superar desafios políticos e pedagógicos ${ }^{14}$.

Com base nos fatores abordados nessa categoria, é relevante, em uma instituição de ensino superior, levar em conta o perfil dos profissionais que atuam em sala de aula com os alunos, pois os professores também fazem parte do patrimônio intelectual da universidade. Professores com perfis compatíveis com os interesses da universidade ou com uma trajetória respeitável em relação a alguma área especifica são importantes influências para os alunos em sua trajetória acadêmica. Esses aspectos se mostraram relevantes no processo de escolha da RM, já que foi um dos fatores mais abordados pelos residentes nas entrevistas, o que sinaliza uma crescente identificação dos alunos com os profissionais que atuam na academia.

\section{Categoria: motivadores sociais}

\section{Comprometimento social}

A respeito das experiências de vida dos residentes e de suas relações construídas no percurso, é importante ressaltar as falas emergentes de dois residentes. 
Eu fui coordenador geral de diretório acadêmico, fui coordenador regional da executiva do curso, da medicina, né?! Regional. [...] E atuo ainda junto com o MAB [Movimento Atingidos por Barragens], trabalhei em Mariana quando teve o desastre, na verdade eu me aproximei bastante do MST pelas questões da agroecologia que eu me aproximei aqui em SC, então eu sempre estive envolvido com movimentos sociais, eu acho que é fundamental na verdade para a medicina na família(R6, médico).

As experiências adquiridas no percorrer da vida são fatores primordiais para a escolha da área de atuação, como corrobora o discurso de R8 (fonoaudióloga): "Eu me envolvi muito em defesa do SUS, também a residência veio como uma oportunidade de estar inserido um pouquinho mais nisso, na vivência do cotidiano do SUS como uma profissional".

Outros depoimentos também valorizaram a experiência com outros movimentos sociais, como participações em trabalhos comunitários de bairros ou atividades sociais proporcionados por meio de ações e programas da universidade.

Pelo fato de o envolvimento com os movimentos sociais emergir como uns dos fatores motivadores importantes na opção pela RM, estudos apontam que a escolha da área de atuação envolve um processo, um elemento que se desenvolve durante a trajetória de vida do indivíduo, que abarca diversas questões sociais, históricas e econômicas ${ }^{15}$.

Portanto, a escolha profissional não é desconexa da história de vida do estudante, o processo de escolha profissional do indivíduo ocorre com a construção dos seus valores e princípios, com a projeção do que anseia ser e de onde quer estar, ou seja, as experiências de vida delimitam e motivam aquilo que o indivíduo deseja para si. Nesse sentido, compreender os fatores que envolvem a construção do desejo de qual carreira profissional seguir pode ser um meio de sensibilizar a importância do trabalho na saúde coletiva, permitindo assim uma maior identificação com seu projeto de ser.

\section{Categoria: políticas públicas}

\section{Auxílio bolsa-residência}

As políticas públicas que visam incentivar os alunos também emergiram como fatores influenciadores. De acordo com R3 (psicóloga): "E a questão da bolsa, eu acho, é muito importante para mim, é uma questão que eu só estou na residência por causa da bolsa, mas a faculdade também eu Pro Uni, eu fiz a faculdade por causas da bolsa”. Apesar de ter menor representação nos discursos dos residentes, o ganho financeiro que a RM permite é apresentado como uma variável potencializadora na opção do aluno pela $\mathrm{RM}^{16}$. Ademais, R1 (dentista) se posiciona: "Eu acho que a bolsa sempre conta, porque, querendo ou não, a gente não sai com um salário desses, né?! Assim recém-formado e uma bolsa bem boa, além de fazer o que eu gosto de estar aqui dentro na unidade de saúde”.

\section{Relação multiprofissional}

A proposta de trabalhar em uma equipe multiprofissional tem como objetivo proporcionar um olhar holístico e humanizado sobre o indivíduo e um compartilhamento de saberes. Essas relações também são percebidas pelos residentes como elementos potencializadores, como é observado na fala de R1 (dentista):
Então essa convivência é muito sadia, até porque está todo mundo no mesmo barco, está todo mundo sofrendo a mesma coisa, já vira uma autoajuda, uma roda de conversa... Todos esses profissionais, juntos, e depois para fazer o PTS [projeto terapêutico singular], discutir caso, cada um dava um pedacinho daquilo que sabia e a gente acabava construindo um todo, como um monte de retalho.

No entanto, apesar do que foi relatado por R1, pode-se perceber que essa vivência compartilhada de saberes não é experienciada por todos os residentes, conforme relata R3 (psicóloga): "Eu achei que seria mais fácil lidar com as outas profissões, eu percebi que não, não é tão fácil... tem algumas áreas também que percebem a importância em trabalhar em conjunto e outras não".

Por fim, segue o relato de R8 (fonoaudióloga) sobre sua compreensão da relação multiprofissional:

É bem mais complexo do que a gente espera assim, né? No sentido que a gente tem que lidar com nossas intenções e o nosso modo de ver, que vai influenciar no nosso fazer, mas também com os dos outros, com os nossos companheiros de trabalho, e eu acho que esse é o grande $Q$ das relações, muito com nossos companheiros e não tanto com quem procura o serviço, e eu acho que esse é grande boniteza do processo e o grande desafio, têm os dois lados.

Os problemas interpessoais ligados à deficiência das matrizes curriculares dos cursos de graduações podem resultar em ações isoladas quanto à sobreposição do cuidado fragmentado contribuindo para a dificuldade na interação entre as profissões ${ }^{7}$. Esse é um fato importante, pois envolve um grupo seleto de pessoas que podem trabalhar de forma harmoniosa, estabelecendo ou não um vínculo sólido no decorrer da residência, o que influencia de forma direta na prática cotidiana do serviço.

Certamente, a relação multiprofissional é uma estratégia do SUS para potencializar o cuidado sobre o sujeito, por meio do cuidado partilhado entre os profissionais de diversas áreas, de modo a proporcionar ao indivíduo um olhar biopsicossocial. Esse olhar holístico sobre o sujeito só é possível por meio da boa comunicação e da troca de experiências, fruto de uma relação saudável entre os residentes, ou seja, por meio da multidisciplinaridade, em que cada profissional contribui com sua área de saber, é possível realizar uma estratégia terapêutica mais eficaz. Portanto, é imprescindível, na atuação multiprofissional, que duas ações ocorram na formação do residente: aprender a trabalhar multiprofissionalmente e conscientizar-se da importância de trabalhar desse modo, sempre respeitando o saber de cada ciência.

\section{A residência multiprofissional e os residentes de Medicina}

Entre os residentes que cursam a RM na saúde da família, é importante notar a diferença do discurso, pois a medicina possui diversas áreas de residências, caso o aluno queira escolher, diferentemente dos demais cursos ligados à saúde que têm somente a RM. Outro diferencial para os alunos que cursaram Medicina e decidiram fazer residência na medicina da família é a segunda bolsa de incentivo dado pelo município, que tem como objetivo atrair mais alunos formados para essa área. 
Quando se analisa o conteúdo apresentado pelos participantes desta pesquisa, é possível compreender mais claramente os fatores motivacionais necessários e influenciadores que resultam na escolha da RM: o construto histórico do sujeito, a diretividade da grade curricular oferecida pela universidade, a escolha de professores com um olhar positivo em relação às questões relacionadas ao SUS para que possam ministrar as aulas e a ligação com movimentos sociais.

Primeiramente, observa-se, no relato de R6 (médico), a visão do SUS percebida pela maioria dos professores do curso de Medicina: "Se você for hoje numa faculdade de Medicina, na sala vão estar falando mal, é um ou outro professor, é tipo eu descobri o SUS no movimento estudantil". E R6 acrescenta:

"[...] há um professor que é referência nesta área, dentro do movimento estudantil da medicina, aí dentro do movimento estudantil da medicina ele fez muito espaço, faz ainda acredito eu. Este profissional sempre foi uma das nossas referências em saúde coletiva e tudo mais história do SUS [...], mas minha escolha pessoal foi basicamente por causa dele".

Toda residência, independentemente da área, pressupõe um corpo docente especializado, entretanto, no discurso de muitos profissionais, a atenção básica é uma especialidade menos valorizada em termos de conhecimento e status financeiro.

Outros pesquisadores corroboram os depoimentos mencionados neste estudo por meio dos discursos que emergiram dos residentes de medicina, em que se reafirma o baixo prestígio em trabalhar na medicina da família, o que é confirmado pela literatura internacional e principalmente pela nacional ${ }^{15,16}$. A cultura disseminada entre os profissionais de medicina exerce grande influência na escolha de outras áreas de atuações e não apenas na atenção básica ${ }^{17}$.

Sobre as questões de trabalho dentro da RM e no SUS, temos o seguinte relato: "A forma como a gente trabalha, o serviço está muito saturado, não tem muito investimento desejado, sabe, nessa parte [...], a gente não dá conta do tanto de pessoas que tem". Muitas vezes, o médico idealizado - ou de referência - dos estudantes de Medicina não é aquele que trabalha no SUS. Esse não reconhecimento é causado por diversos fatores, falta de retorno financeiro, desvalorização profissional e sucateamento do SUS, visto que o governo implementou de forma desorganizada a reforma sanitária. Percebe-se esse descaso do governo com o SUS pela redução de investimento no setor, pela má administração dos recursos, pela ineficácia gerencial e pela não regulamentação dos planos privados, que, por sua vez, continua a alimentar a privatização, o que reduz a saúde pública aos carentes da população brasileira e estrutura um quadro de precarização e insuficiência do SUS ${ }^{8,12-14}$.

Os problemas expostos pelos residentes de Medicina na especialidade saúde da família demonstram os vários níveis de ações necessárias para tornar a RM uma especialidade mais atrativa para esse grupo, desde o processo de formação do profissional da medicina, que precisa ser sensibilizado pelo corpo docente sobre a importância da reforma sanitária e do papel do SUS. Devem-se se considerar também outros fatores, como melhores condições de trabalho dentro do sistema público, melhorias necessárias desde os instrumentos técnicos utilizados no exercício profissional até a qualificação da mão de obra e uma equipe que possa ser capaz de atender às demandas do território, sem sobrecarregar os que estão inseridos no sistema público, para exercício de um trabalho com maior alcance e resolutividade.

Com base nessas questões e depoimentos dos residentes em medicina da família, constata-se que muitos graduandos não têm como primeira escolha essa especialidade. Muitos buscam essa residência para outros fins, como menciona R6 (médico): "Porque a gente ganha duas bolsas, e muita gente que tá na medicina não tem perfil para trabalhar na multi, está lá por causa da bolsa, ou pelos pontos que ganham para fazer outra residência”. De acordo com o Programa Mais Médicos do governo federal ${ }^{5}$, os médicos que atuam na RM ganham uma segunda bolsa cujo propósito é atrair médicos para a atenção básica e saúde da família, recebendo assim uma renda líquida no valor de dez mil reais, além de uma pontuação para a prova de outra residência. Ainda segundo R6 (médico): "A procura da medicina é pouca em medicina da família, a medicina da família é uma especialidade ainda pouco valorizada, é antiga, mas se tornou especialidade há pouco tempo e é desvalorizada". O Brasil possui cerca de 4.022 especialistas em medicina da família, o que corresponde a $1,2 \%$ do total de médicos ${ }^{17}$. Esse número reflete a priorização das especialidades de alta complexidade ou da medicina de alta renda, demonstrando uma inversão piramidal no tocante à formação médica. Como as áreas da medicina que envolve saúde coletiva e atenção básica não são atraentes, a formação de médicos para o serviço público não acompanha a alta demanda do SUS. A motivação dos alunos de Medicina por especializações que apresentam um maior prestígio social e retorno financeiro, além de contar com fatores de maiores investimentos tecnológicos em outras especialidades, explicita a necessidade de procurar novas formas de pensar o ensino no curso médico, partindo de uma visão generalista, com foco no cuidado e na prevenção de doenças, para um olhar abrangente do indivíduo capaz de enfatizar a promoção da saúde.

O depoimento de R6 é corroborado por R5 (médica):

Prestei prova e não passei para psiquiatria... tinha a residência de medicina da família, que já estava cogitando isso há muito tempo; se eu não passar, eu posso fazer a medicina da família... eu precisava de um pouquinho mais de maturidade, acho que consegui isso nesses dois anos e eu ganho os $10 \%$ depois desses dois anos na minha prova de psiquiatria.

Essa fala demonstra que a RM pode ser considerada uma experiência provisória para o médico.

Relatos de pesquisas confirmam os dados apontados pelos residentes, ou seja, o programa não se tornou um fator influenciador na decisão de atuação da medicina da família, mas os incentivos dados pelo programa de RM ajudaram, de maneira provisória, os médicos graduados a trabalhar na atenção básica, pois a falta de perspectiva de carreira aliada a uma expectativa de renda maior leva os acadêmicos a direcionar as carreiras a outras especialidades e afastar-se da medicina da família ${ }^{17}$.

Portanto, com base no relatos aqui expostos, é possível supor que os maiores motivadores para um médico estar na saúde coletiva e atenção básica são os fatores sociais, como escolhas políticas e envolvimentos com causas sociais, enquanto aqueles que preferem outras especialidades têm como motivadores diversos fatores que contemplam o sucateamento e a saturação do serviço no SUS, a perspectiva de melhores salários, o

7 REVISTA BRASILEIRA DE EDUCAÇÃO MÉDICA

74 (3) : e083; 2020 
prestigio social, entre outros.

Em contrapartida, a formação dentro da modalidade residência é percebida tanto pelos alunos da residência como por aqueles que estão na graduação como uma possibilidade de apacitação profissional diferenciada, que possibilita o desenvolvimento de saberes e competências profissionais por meio de uma prática supervisionada.

Entre os fatores que levam os graduandos a ser instigados pela RM, destacam-se a saúde coletiva/SUS, a atenção básica e o comprometimento social. Segundo Oshina et al. ${ }^{7}$, o servidor público ideal é aquele que simpatiza com o coletivo, proporcionando um atendimento humanizado, e que respeita os aspectos éticos da profissão, mesmo tendo pouca experiência.

Nesse ínterim, destacam-se algumas dificuldades encontradas no processo de engajamento dos graduandos de Medicina na RM e dos próprios residentes que já atuam na atenção básica. As experiências dos alunos residentes quanto às questões políticas e administrativas do SUS apontam a necessidade de investimento no sistema público de saúde, a falta de mão de obra e de aparelhos instrumentais, e a saturação de demanda, o que contribui para uma experiência menos positiva dos residentes para o exercício do trabalho. Outras dificuldades apontadas são a organização do serviço e os relacionamentos interpessoais com colegas de trabalho. Ressalva-se que tais aspectos não foram apontados como motivos para os graduandos não realizarem a RM. De modo geral, a residência ainda tem se mostrado uma experiência positiva de aprendizado e oportunidade de conhecer o SUS além da teoria apresentada na graduação.

Quanto aos médicos da RM, é importante perceber que essa experiência não tem sido suficiente para mantê-los no SUS. Os médicos têm experimentado a RM como uma formação provisória para que possam alcançar outros objetivos. Dessa forma, o presente artigo aponta para o desafio de fazer com que o trabalho no SUS seja tão atrativo quanto o trabalho em hospitais e clínicas particulares. O desenvolvimento de um sistema que prestigie o médico do SUS e a melhoria do serviço desse sistema são algumas das estratégias que podem ser pensadas para que o trabalho no sistema público de saúde se torne mais motivador e atrativo para os médicos.

\section{CONSIDERAÇÕES FINAIS}

Neste estudo, investigamos os condicionantes motivacionais para a escolha do programa de RM de uma universidade situada no Vale de Itajaí, em Santa Catarina. Após a coleta e análise dos dados, foi possível perceber que são diversas as motivações para realizar a RM entre os alunos da graduação e os residentes ingressos na RM. Entre os motivos, os mais representativos foram a experiência profissional, interesse em saúde coletiva/SUS e comprometimento social.

Com base nos resultados obtidos, percebe-se que, entre os motivadores individuais, a experiência profissional apresentou a maior frequência de respostas, o que pode apontar a insegurança na inserção no mercado, a busca por capacitação que auxilie no processo de escolha da RM e o interesse pela saúde coletiva/SUS. Cabe salientar que o maior interesse por essa temática está relacionado às mudanças sociais da década de 1980 em diante e àquelas realizadas nas grades curriculares das universidades.

Além disso, os motivadores sociais mostraram-se aspectos importantes. As experiências relacionadas às causas sociais e à defesa do SUS parecem colaborar para uma maior noção de comprometimento social e consciência coletiva, o que pode servir de motivador para a realização de uma RM voltada à atenção básica.
Com relação aos fatores institucionais, observou-se a importância de uma proposta bem estruturada e de um corpo docente identificado com o SUS e seus princípios e objetivos, o que permite ao aluno aproximar-se da residência com maior identificação e entendimento a respeito do programa. Outros fatores relacionados às estruturas físicas e tecnológicas não foram levantados pelos residentes, o que pode evidenciar a importância dos pontos supracitados. Todavia, os residentes, em sua maioria, cursaram a graduação na mesma instituição em que realizam a RM. Esse fator é importante porque foi identificado nas entrevistas que, desde a graduação, os conteúdos referentes à saúde coletiva e ao SUS eram ideologias prestigiadas, o que nos faz levantar a hipótese de que um corpo docente identificado e estruturado pode colaborar nesse processo de opção pela RM.

O presente estudo, num primeiro momento, tinha como intuito identificar os aspectos motivacionais individuais e sociais para a realização da RM, porém, durante a realização da pesquisa, emergiu uma quantidade grande de conteúdo demandando a criação de duas novas categorias (políticas públicas e institucionais). Também foi considerado importante abarcar a realidade da RM a partir das falas dos residentes, assim como a pluralidade e diversidade de conteúdos emergentes.

A disponibilidade de tempo para agendamentos dos entrevistados, por conta dos compromissos acadêmicos e pessoais e dos sucessivos feriados, foi um elemento limitante na realização da pesquisa. Além disso, devem-se apontar como aspectos limitadores o processo burocrático referente à realização de pesquisas em sala de aula e as atividades de estágios em que os graduandos dos últimos períodos estão envolvidos. Essas considerações demonstram a necessidade de explorar o tema em pesquisas futuras, para averiguar hipóteses potencialmente identificadas neste estudo. Contudo, a presente pesquisa tem sua importância por ser umas das poucas em sua temática no âmbito nacional e que auxilia no levantamento de possíveis categorias para os próximos trabalhos.

Conclui-se que a falta de pesquisas nessa temática confirma o pouco interesse de pesquisadores em motivar os alunos a participar do programa de RM. A temática abordada mostra-se um importante alvo para pesquisa, sendo o SUS um grande órgão de serviço público que necessita de profissionais capacitados para atuação e conta como umas das estratégias para captação de força de trabalho especializada. Além disso, o próprio programa de RM ressalta a importância de compreender quais fenômenos estão envolvidos na motivação de o aluno realizar a RM.

\section{REFERENNCIAS}

1. De Marco MA, Lucchese AC, Dias CC. Psicologia médica e semiologia integrada. In: Puccini RF, Sampaio LO, Batista NA, editores. A formação médica na Unifesp: excelência e compromisso social. São Paulo: Unifesp; 2008. p. 263-88

2. Brasil. Lei $n^{\circ} 11.129$, de 30 de junho de 2005, institui a Comissão Nacional de Residência Multiprofissional em Saúde no âmbito do Ministério da Educação. Brasília, 2005.

3. Brasil. Residência multiprofissional. Brasília; 2005 [acesso em 7 jun 2017]. Disponível em: http://portal.mec.gov.br/buscageral/247-programas-e-acoes-1921564125/residencia-medica2137156164/12501-residencia-multiprofissional.

4. Nascimento DDG, Oliveira MAC. Reflexões sobre as competências profissionais para o processo de trabalho nos núcleos de apoio à saúde da família. Mundo saúde 2010; 34(1): 92-6. 
5. Brasil. Programa Mais Médicos. Brasília; 2018 [acesso em 5 maio 2020] Disponível em: http://maismedicos.gov.br/.

6. Bohoslavsky R. Orientação vocacional: a estratégia clínica. São Paulo: Matrins Fontes; 1977.

7. Oshina AMMY, Besegato JF, Lima CV, Noronha MS, Hoeppner MG, Caldarelli PG. Perfil, atuação e satisfação de cirurgiões-dentistas em residências multiprofissionais em saúde da região Sul do Brasil. Revista da Associação Brasileira de Ensino Odontológico 2018;18(1):134-45.

8. Bardagi M, Lassance MCP, Pardiso AC, Menezes IA de. Escolha profissional e inserção no mercado de trabalho: percepções de estudantes formandos. Psicol. esc. educ. 2006;10(1); 69-82.

9. Minayo MCS. Pesquisa social: teoria, método e criatividade. Rio de Janeiro: Vozes; 2001.

10. Cunha YFF, Vieira A, Roquetr FF. Impacto da residência multiprofissional na formação profissional em um hospital de ensino de Belo Horizonte. X Simpósio de Gestão e Excelência e Tecnologia; 2013. Belo Horizonte. SEGET. UFMG. [acesso em 4 mai 2020]. Disponível em:https://www.aedb.br/seget/arquivos/ artigos13/15318312.pdf

11. Gonçalves CR, Cruz MT, Oliveira MP, Morais AJD, Moreira KS, Quintão CA, et al. Human resources: critical factor for primary health networks. Saúde debate 2014;38(100):26-34.

12. Cordeiro H. O Instituto de Medicina Social e a luta pela reforma sanitária: contribuição à história do SUS. Physis 2004;2(14):343-62.

13. Freire RP, Guimarães RM, Henriques RLM, Chaves MMY. O currículo integrado da faculdade de enfermagem UERJ: uma reflexão sobre a formação de recursos humanos para o SUS. Rev. bras. enferm. 2003;56(4):381-4 [acesso em 4 mar 2020]. Disponível em: http://www.scielo.br/scielo.php?script=sci_arttext\&pid=S0034$71672003000400014 \& \operatorname{lng}=$ en.

14. Miranda Neto MV, Leonello VM, Oliveira MAC. Residências multiprofissionais em saúde: análise documental de projetos políticopedagógicos. Rev. bras. enferm. 2015;68(4):586-93.
15. Borges RCP, Coutinho MC. Trajetórias juvenis: significando projetos de vida a partir do primeiro emprego. Revista bras. orientaç. prof. 2010;11(2):189-200.

16. Lima GPV, Pereira ALF, Guida NFB, Progianti JM, Araújo CLF, Moura MAV. Expectations, motivations and perceptions of nurses on the nurse-midwifery specialization course in the residence modality. Esc. Anna Nery Rev. Enferm. 2015;19(4):593-9. [acesso em 4 mar 2020]. Disponível em: [acesso em 4 mar 2020]. Disponível em:DOI: 10.5935/1415-2762.20180035.

17. Issa AHTM, Garcia-Zapata MTA, Rocha AC, Sandré BB, Dutra ACF, Martins ILO, et al. Fatores influenciadores na escolha pela medicina de família segundo estudantes numa região neotropical do Brasil. Rev. Educ. Saúde 2017;2(5):56-65. DOI: 10.29237/2358-9868.2017v5i2.p56-65.

\section{CONTRIBUIÇÃO DOS AUTORES}

Jamir Sardá Júnior orientou a pesquisa e foi responsável pelo desenho metodológico, pela análise dos dados e pela elaboração do artigo. Israel Domingos Dias participou da coleta de dados, análise dos dados e elaboração do artigo. Marco Aurélio da Ros e Gabrielly Bos de Oliveira foram os responsáveis pela elaboração e revisão do artigo.

\section{CONFLITO DE INTERESSES}

Os autores declaram não haver conflito de interesses neste estudo.

\section{ENDEREÇO PARA CORRESPONDÊNCIA}

Jamir Sardá Júnior.Avenida Campeche, 1157, C-1, 403. Campeche, Florianópolis, SC, Brasil. CEP: 88063-300.

E-mail: jamirsarda@hotmail.com 